Article

\title{
Evaluation of Whole-Body Vibration Exercise on Neuromuscular Activation Through Electromyographic Pattern of Vastus Lateralis Muscle and on Range of Motion of Knees in Metabolic Syndrome: A Quasi-Randomized Cross-Over Controlled Trial
}

Cintia Renata de Sousa-Gonçalves ${ }^{1,2}$, Laisa Liane Paineiras-Domingos ${ }^{1,2,3}$ (D), Ygor Teixeira-Silva 1,2, Thais Amadeu 1(D), Adriana Pereira da Silva Lírio², Arlete Francisca-Santos ${ }^{2}$, Luiz Felipe Ferreira De Souza ${ }^{2}$ (D), Mario José dos Santos Pereira ${ }^{2}$, Maria Eduarda Souza Melo-Oliveira 2,4 Alexandre Gonçalves de Meirelles 2,4, Glória Maria Guimarães-Lourenço ${ }^{2,4}$, Aline Reis-Silva 2,4 , Eloá Moreira-Marconi 2,5 (D, Marcia Cristina Moura-Fernandes ${ }^{2,5}$, Vinicius Layter Xavier ${ }^{6} \mathbb{D}$, Alessandra da Rocha Pinheiro Mulder ${ }^{7}$, Ana Cristina Rodrigues Lacerda ${ }^{8}$ (D, Vanessa Amaral Mendonça ${ }^{8}$, José Alexandre Bachur ${ }^{9}$, Redha Taiar ${ }^{10, * \mathbb{D}}$, Alessandro Sartorio ${ }^{11}$, Danúbia da Cunha de Sá-Caputo ${ }^{1,2,3}$ and Mario Bernardo-Filho ${ }^{2}$ (D)

1 Programa de Pós-Graduação em Ciências Médicas, Faculdade de Ciências Médicas, Universidade do Estado do Rio de Janeiro, Rio de Janeiro 20.551-030, Brazil; ci.renata@gmail.com (C.R.d.S.-G.); laisanit@gmail.com (L.L.P.-D.); silvarogy@hotmail.com (Y.T.-S.); tpamadeu@gmail.com (T.A.); dradanubia@gmail.com (D.d.C.d.S.-C.)

2 Laboratório de Vibrações Mecânicas e Práticas Integrativas, Departamento de Biofísica e Biometria, Instituto de Biologia Roberto Alcântara Gomes e Policlínica Américo Piquet Carneiro, Universidade do Estado do Rio de Janeiro, Rio de Janeiro 20950-003, Brazil; adrianaliriolavimpi@gmail.com (A.P.d.S.L.); fisioarlete@hotmail.com (A.F.-S.); lumadaragu@gmail.com (L.F.F.D.S.); mariojsp@gmail.com (M.J.d.S.P.); mariaeduardaoliveira@hotmail.com (M.E.S.M.-O.); meirelles.ale@gmail.com (A.G.d.M.); dra.glorialourenco@gmail.com (G.M.G.-L.); fisioalinereis@hotmail.com (A.R.-S.); eloamarconi@gmail.com (E.M.-M.); marciafernandesfisio@hotmail.com (M.C.M.-F.); bernardofilhom@gmail.com (M.B.-F.)

3 Faculdade Bezerra de Araújo, Rio de Janeiro 23052-180, Brazil

4 Programa de Pós-graduação em Saúde, Medicina Laboratorial e Tecnologia Forense, Universidade do Estado do Rio de Janeiro, Rio de Janeiro 20950-003, Brazil

5 Programa de Pós-Graduação em Fisiopatologia Clínica e Experimental, Instituto de Biologia Roberto Alcântara Gomes, Universidade do Estado do Rio de Janeiro, Rio de Janeiro 20.551-030, Brazil

6 Departamento de Estatística, Instituto de Matemática e Estatística, Universidade do Estado do Rio de Janeiro, Rio de Janeiro 20550-900, Brazil; viniciuslx@ime.uerj.br

7 Departamento de Nutrição, Instituto de Nutrição e Policlínica Américo Piquet Carneiro, Universidade do Estado do Rio de Janeiro, Rio de Janeiro 20550-900, Brazil; alessandra.mulder@gmail.com

8 Faculdade de Ciências Biológicas e da Saúde, Universidade Federal dos Vales do Jequitinhonha e Mucuri, Diamantina 39.100.000, Brazil; lacerdaacr@gmail.com (A.C.R.L.); vaafisio@hotmail.com (V.A.M.)

9 Centro Universitário de Franca, Franca 14401-426, SP, Brazil; jabachur@hotmail.com

10 GRESPI, Université de Reims, 51100 Reims, France

11 Istituto Auxologico Italiano, IRCCS, Experimental laboratory for Auxo-endocrinological Research, Division of Metabolic Diseases \& Auxology, 28824 Verbania, Italy; sartorio@auxologico.it

* Correspondence: redha.taiar@univ-reims.fr; Tel.: +33-677-944628

Received: 16 October 2019; Accepted: 15 November 2019; Published: 20 November 2019

Abstract: Metabolic syndrome (MetS) is related to overweight and obesity, and contributes to clinical limitations. Exercise is used for the management of MetS individuals, who are often not motivated 
to perform this practice. Whole body vibration exercise (WBVE) produces several biological effects, besides being safe, effective, and feasible for MetS individuals. This pseudo-randomized and cross-over controlled trial study aimed to analyze the effects of WBVE on MetS individuals' neuromuscular activation using the surface electromyography (sEMG) pattern (root mean square (RMS)) of the vastus lateralis (VL) muscle and on the range of motion (ROM) of the knees. Participants $(n=39)$ were allocated to two groups: the treatment group (TG), which was exposed to WBVE, and the control group (CG). WBVE interventions were performed twice a week, for a period of 5 weeks. ROM and sEMG were analyzed at baseline, after the first session, and before and after the last session. sEMG (\%RMS) significantly increased in the acute effect of the last session of WBVE (108.00 \pm 5.07 , $\mathrm{p}<0.008$, right leg; $106.20 \pm 3.53, \mathrm{p}<0.02$, left leg) compared to the CG. ROM did not significantly change in TG or CG. In conclusion, 5 weeks of WBVE exerted neuromuscular effects capable of increasing VL muscle RMS in individuals with MetS, this effect being potentially useful in the physical rehabilitation of these individuals.

Keywords: metabolic syndrome; whole body vibration exercise; range of motion of the knees; surface electromyographic pattern; neuromuscular activation; biomechanics

\section{Introduction}

In the modern world, unhealthy lifestyles, including physical inactivity and bad dietary habits, contribute to the development and spread of diseases associated with metabolic commitment, such as metabolic syndrome (MetS). MetS is defined as a clustering of metabolic abnormalities, such as central obesity (increased waist circumference), dyslipidemia, hyperglycemia, and hypertension, according to the guidelines of the International Diabetes Federation (IDF) [1,2].

Yang et al. pointed out that overweight and obesity are emerging major health issues, which are closely related MetS [3]. Body mass excess can promote adipose tissue stored in the abdominal cavity and intramuscular adipose tissue (IMAT) [4,5]. It is known that these conditions directly affect the biomechanics of movements [6-8], leading to decreased mobility, strength, and ability to perform common activities of daily living $[6,9,10]$. In obese individuals, lower extremity overuse injury is caused by multiple mechanisms, including increased load bearing with ambulation, altered gait biomechanics due to abnormal body mass distribution, a systemic pro inflammatory state [7,11-13]. The affected joint kinetics may increase the risk of musculoskeletal injury, with the development of osteoarthritis, especially in the knees [7,14], and the impairment of the range of motion (ROM) $[7,15]$. Reduced ROM can imply the limitation of the knee flexion [15], which is required to perform activities of daily living [16]. ROM is a parameter of physical evaluation, since it can allow the identification of joint and muscle limitations. Moreover, it is used for the evaluation of individuals during the rehabilitation process [17].

In obese individuals, the lower limb muscles (flexors and extensors) are frequently committed $[9,10]$. In consequence, decrease of muscle strength and power, and premature fatigue [6] are observed, leading to impaired motor performance [18]. As these individuals are not motivated to practice regular exercise, methods to increase adherence including exercises that minimize the impact on the joints are necessary [19]. Among the different kinds of exercises, whole body vibration exercise (WBVE) may be an option for the management of obese individuals [20,21].

WBVE involves exposing individuals to mechanical vibrations that are produced in a vibrating platform (VP). These vibrations are transmitted to the body of the individual that is in contact with the base of the VP. Some parameters must be adjusted (frequency, peak-to-peak displacement, and peak acceleration) considering the clinical condition of the individual [22]. Similarly, if the person is sitting on an auxiliary conventional chair [23] or wheelchair [24] with the feet on the base of VP, the individual will also experience WBVE. 
Authors evaluated the effects of WBVE on MetS individuals, and important responses were observed, such as improvement of quality of life and flexibility $[25,26]$. Moreover, WBVE is safe and effective to treat muscle complications in populations with different disorders [27-31] as well as healthy individuals [32,33].

Surface electromyography (sEMG) is an adequate tool to evaluate neuromuscular effects of WBVE [27,34-36]. An increased sEMG activity after WBVE indicates that more motor units are recruited [34].

It is well described that WBVE can improve joint mobility [29,37,38]. Moreover, Wang et al. found that WBVE in combination with quadriceps resistance exercise compared with quadriceps resistance exercise alone showed significantly greater improvement in knee flexion and extension in individuals with knee osteoarthritis [39].

The aim of this study was to analyze the effects of WBVE on neuromuscular activation through the electromyographic pattern of the vastus lateralis muscle and on range of motion of the knees in MetS individuals. The study hypothesis was that WBVE would increase neuromuscular activation and range of motion of the knees of MetS individuals.

\section{Materials and Methods}

This was a quasi-randomized cross-over controlled trial, where 39 individuals with MetS were selected to evaluate the effect of WBVE on neuromuscular activation and range of motion of the knees. Individuals were allocated, as they arrived, to the control (CG) or treatment group (TG). The study protocol was approved by the Research Ethics Committee of the Hospital Universitário Pedro Ernesto (HUPE), Universidade do Estado do Rio de Janeiro (UERJ), with the number CAAE 54981315.6.0000.5259, and was registered in the Registro Brasileiro de Ensaios clínicos (ReBEC) (RBR 2bghmh).

Recruitment took place from April 2014 to January 2016 following screening of MetS individuals by the medical staff at HUPE-UERJ, Brazil. The WBVE protocol was performed in the Laboratório de Vibrações Mecânicas e Práticas Integrativas (LAVIMPI), UERJ. Participants signed a consent form before any procedures, and the principles embodied in the Declaration of Helsinki were followed.

\subsection{Sample Size}

The sample size was determined based on a study by Sá-Caputo et al. [26], involving individuals with MetS exposed to WBVE, using an online calculator of the Laboratório de Epidemiologia e Estatística (LEE), Faculdade de Medicina, USP, São Paulo, Brazil [40]. For a statistical power of 95\%, a sample size of 13 individuals was calculated [26,40]

\subsection{Inclusion and Exclusion Criteria}

For this study, the inclusion criteria were age over 40 years (male and female gender) and a diagnosis of MetS. All participants were selected by a clinical physician, who diagnosed MetS according to the International Diabetes Federation criteria [1].

The exclusion criteria comprised very high blood pressure $(\geq 180 / 110 \mathrm{mmHg})$, cardiovascular disease (coronary artery disease or stroke), neurological, musculoskeletal, or rheumatologic disease that do not permit to be on the VP, refusal to sign the consent form for participation in the study, and fear of being on the VP due to its movements.

\subsection{Interventions}

Eligible participants ( $n=39$ ) were allocated to one of two groups: TG and CG. In the TG, the individuals performing the protocol with the VP turned on, while in the CG, the VP was turned off. After a 2-month washout (i.e., the period of time between the two interventions), the participants were crossed-over to the other group [41]. All procedures were performed by health professionals previously trained by experienced trainers to perform this protocol. Intra-rater reliability was not 
performed. The VP (Novaplate Fitness Evolution, DAF Produtos Hospitalares Ltda., São Paulo, Brazil) was a side alternating platform, in which the right site is displaced down while the left side is displaced up, and vice versa [26,42].

In the first session of the TG, all the individuals were seated on a chair placed in front of the platform with a $130^{\circ}$ knee flexion. Their feet, shoeless, were placed on the base of the platform, alternately in three positions (peak to peak displacements of 2.5, 5.0, and $7.5 \mathrm{~mm}$ ) and with a frequency of $5 \mathrm{~Hz}$. The working time in each position was 1 minute followed by 1 minute of rest. This sequence was performed three times. This procedure is shown in Figure 1.

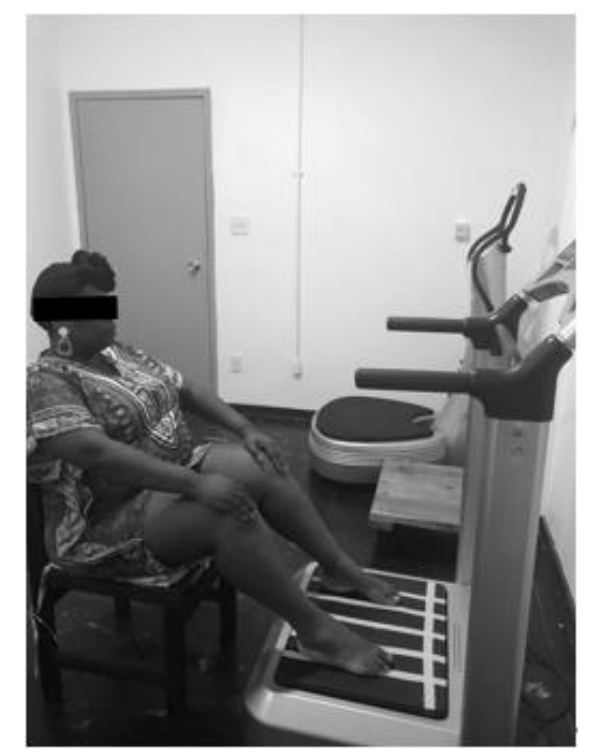

Figure 1. Individual performing whole-body vibration exercise seated on a chair placed in front of the vibrating platform.

From the second to the last session ( $10^{\text {th }}$ session), the individuals were subjected to exactly the same protocol of the first session; however, they were standing on the base of the VP in a squat position $\left(130^{\circ}\right.$ knee flexion), and the frequency was progressively increased by 1 unit per session up to $14 \mathrm{~Hz}$ in the last session. The WBVE session was performed twice per week during 5 weeks. This procedure is shown in Figure 2.

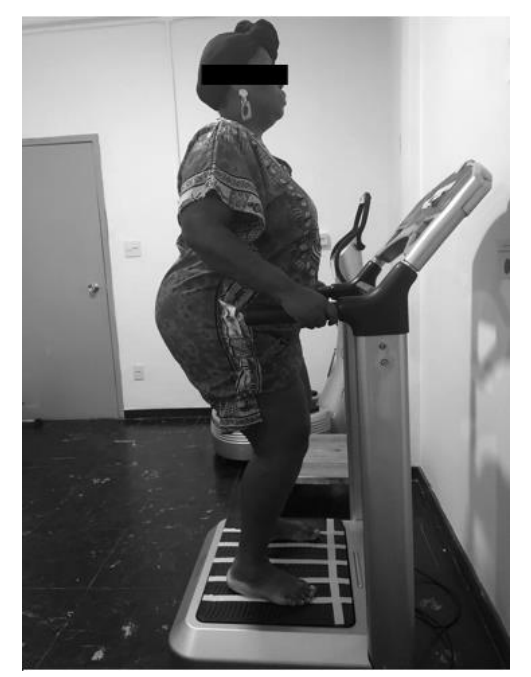

Figure 2. Individual performing WBVE in a standing position on the vibrating platform. 


\subsection{Outcome Measures}

\subsubsection{Anthropometric Evaluation}

Anthropometric data (body mass, height) of the participants were assessed by a single operator using a balance with a stadiometer (Micheletti MIC 200PPA, São Paulo, Brazil). The waist circumference (WC) was measured with a tape in the horizontal plane, midway between the inferior margin of the ribs and the superior border of the iliac crest, in agreement with the IDF recommendations [1]. The body mass index (BMI) was calculated dividing body mass in kilograms by squared height in meters [43].

\subsubsection{Evaluation of Knee Range of the Motion}

A standard digital goniometer (EMG 830RF, EMGSystem ${ }^{\circledR}$, São Paulo, Brazil) was used to measure the active ROM [44-46] of the knees during flexion from extension. The goniometer was properly fixed on the skin with tape on the lateral side of the knee joint, alternately right and left, to measure the flexion angle. Knee angles related to ROM were recorded on a computer. These procedures are shown in Figure 3.

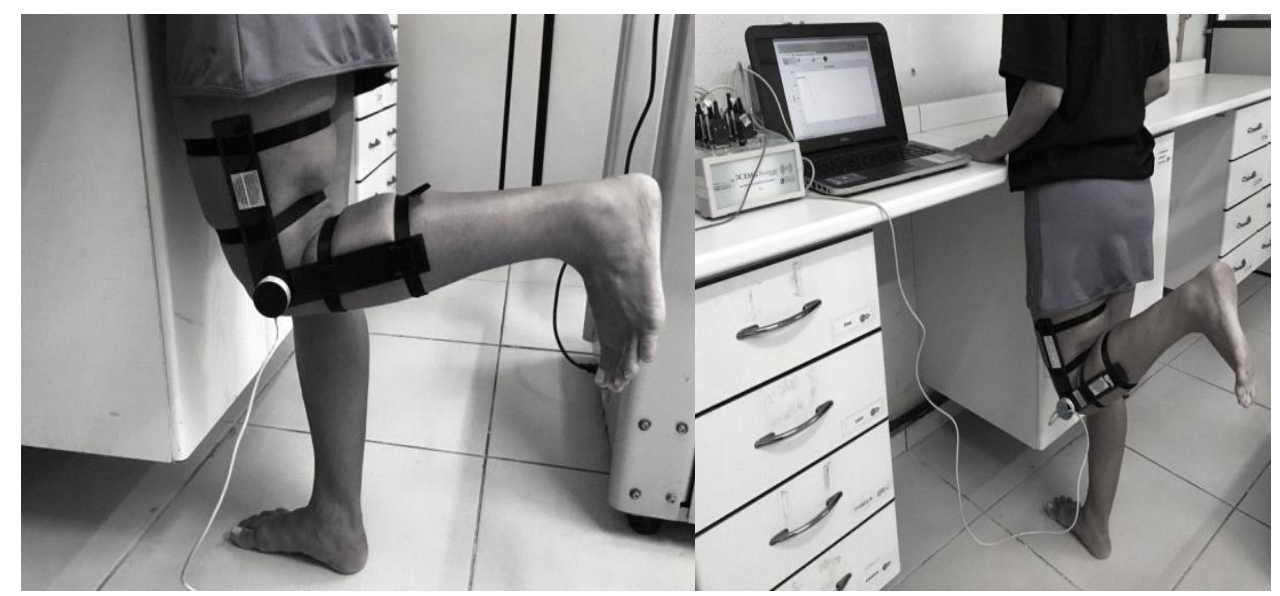

Figure 3. Position of the goniometer on the lower limb for measurement of knee range of motion (ROM).

ROM was determined before and after the first session (acute effect of the first session). The same procedure was performed in the last session (acute effect of the last session). In addition, comparisons were made before the first session and before the last session (cumulative effect) [47]. The percentage of the alteration of ROM (\%AROM) in each condition was calculated dividing the ROM after the session by the ROM before the intervention (acute effect of the first and of the last session) multiplied by 100 . The \%ROM to the cumulative effect in each condition was calculated by dividing the value of ROM before the last session by the ROM before the first session multiplied by 100 .

\subsection{Surface Electromyography (sEMG) Instrumentation and Measurement}

The neuromuscular activity of the vastus lateralis (VL) muscle was evaluated following the recommendations of the Surface ElectroMyoGraphy for the Non-Invasive Assessment of Muscles (SENIAM) regarding skin preparation and fixation of the electrodes in the specified positions related to the VL muscle [48], and the reference electrode was positioned on the spinous process of C7. The sEMG signal was collected in microvolts $(\mu \mathrm{V})$ in a computer and was analyzed using the root mean square (RMS) (EMG832WF, EMGSystem ${ }^{\circledR}$, São Paulo, Brazil). In the sEMG assessment, the individuals were asked to sit on a chair with the back straight, feet approximately shoulder-width apart and placed on the floor, and the arms crossed over the chest. Then, they were instructed to perform five repetitions of sitting and standing [49]. 
The RMS amplitude signal was recorded before and after the first session (acute effect of the first session), and before and after the last session (acute effect of the last session). The \%RMS in each condition was calculated dividing the RMS after the session by the RMS before the session (acute effect of the first and of the last session) multiplied by 100 . The \%RMS to the cumulative effect was calculated in each condition by dividing the value of the RMS before the last session by the RMS before the first session multiplied by 100 .

\subsection{Statistical Analysis}

Statistical analyses were performed using GraphPad Prism 6. The normality of the data was evaluated with the Shapiro-Wilk test. For the comparison of paired nonparametric values, the Wilcoxon Signed-Rank test was used. For the comparison of the two groups (TG and CG), the Mann Whitney test was used. The comparison of the cumulative effect of ROM between the groups was performed using the difference $(\Delta)$ between the value before the first session and that after the last session. The difference was considered significant when $\mathrm{p} \leq 0.05$. The descriptive statistics used were mean and standard error, since the focus of the work was the effect of the intervention.

\section{Results}

The anthropometric data of the participants are reported in Table 1. There were no significant differences between the two groups ( $p>0.05$ ). According to IDF [2], participants with increase in WC values have more probability to develop MetS.

Table 1. Anthropometrics data of the individuals of the study.

\begin{tabular}{cccc}
\hline Anthropometrics & CG $(\mathbf{n}=\mathbf{1 7})$ Mean $\pm \mathbf{S E}$ & TG $(\mathbf{n}=\mathbf{2 2})$ Mean $\pm \mathbf{S E}$ & $\mathbf{P}$ \\
\hline Height $(\mathrm{cm})$ & $1.62 \pm 0.01$ & $1.63 \pm 0.01$ & 0.58 \\
Body mass $(\mathrm{kg})$ & $88.8 \pm 4.08$ & $83.1 \pm 3.65$ & 0.46 \\
BMI $\left(\mathrm{kg} / \mathrm{m}^{2}\right)$ & $33.5 \pm 1.56$ & $31.3 \pm 1.12$ & 0.25 \\
Age $($ years $)$ & $58.1 \pm 2.07$ & $60.7 \pm 1.91$ & 0.40 \\
WC $(\mathrm{cm})$ & $108 \pm 3.58$ & $103 \pm 2.57$ & 0.11 \\
\hline CG:
\end{tabular}

CG: control Group; TG: treatment group; SE: standard error; BMI: body mass index; WC: waist circumference.

The acute effects of WBVE on the ROM of the right and left knees in the first session are shown in Table 2. No significant changes in ROM were observed in either of the groups (CG and TG) or in the comparison between them. Although no significant differences $(p>0.05)$ were detected, the \%AROM of the right knee of the participants in the CG decreased slightly $(85.65 \%)$, while that of the left knee increased slightly $(107.21 \%)$. The \%AROM of the right and left knees of the participants in the TG decreased slightly $(98.09 \%$ and $98.10 \%$, respectively).

Table 2. Acute effects on range of the motion of right and left knees in the first session.

\begin{tabular}{cccccccc}
\hline Knee & \multicolumn{2}{c}{ CG } & & TG & CG $\times$ TG \\
\cline { 2 - 8 } & $\begin{array}{c}\text { Before } \\
\text { Mean } \pm \text { SE } \\
\text { (Degrees) }\end{array}$ & $\begin{array}{c}\text { After } \\
\text { Mean } \pm \text { SE } \\
\text { (Degrees) }\end{array}$ & P & $\begin{array}{c}\text { Before } \\
\text { Mean } \pm \text { SE } \\
\text { (Degrees) }\end{array}$ & $\begin{array}{c}\text { After } \\
\text { Mean } \pm \text { SE } \\
\text { (Degrees) }\end{array}$ & $\begin{array}{c}\text { P } \\
\text { P }\end{array}$ \\
\hline Right knee & $94.13 \pm 6.89$ & $80.63 \pm 9.50$ & 0.29 & $99.47 \pm 7.12$ & $97.58 \pm 6.86$ & 0.62 & 0.59 \\
Left knee & $94.11 \pm 6.91$ & $100.90 \pm 2.74$ & 0.25 & $99.37 \pm 7.16$ & $97.49 \pm 6.88$ & 0.62 & 0.90 \\
\hline
\end{tabular}

CG: control group; TG: treatment group; SE: standard error.

Table 3 shows the acute effects of WBVE on the ROM of the right and left knees in the last session. No significant changes were observed in either of groups (CG and TG) or in the comparison between CG and TG. Although no significant differences ( $p>0.05$ ) were detected, the \%AROM of the right knee and of the left knee of the participants in the CG increased slightly (102.17\% and $103.96 \%$, respectively). 
The \%AROM of the right knee of the participants of the TG decreased slightly (98.67\%), and that of left knee increased (102.04\%).

Table 3. Acute effects on range of the motion of right and left knees in the last session.

\begin{tabular}{|c|c|c|c|c|c|c|c|}
\hline \multirow{2}{*}{ Knee } & \multicolumn{3}{|c|}{ CG } & \multicolumn{3}{|c|}{ TG } & \multirow{2}{*}{$\begin{array}{c}\mathrm{CG} \times \mathrm{TG} \\
\mathbf{P}\end{array}$} \\
\hline & $\begin{array}{c}\text { Before } \\
\text { Mean } \pm \text { SE } \\
\text { (Degree) }\end{array}$ & $\begin{array}{c}\text { After } \\
\text { Mean } \pm \text { SE } \\
\text { (Degree) }\end{array}$ & $\mathbf{P}$ & $\begin{array}{c}\text { Before } \\
\text { Mean } \pm \text { SE } \\
\text { (Degree) }\end{array}$ & $\begin{array}{c}\text { After } \\
\text { Mean } \pm \text { SE } \\
\text { (Degree) }\end{array}$ & $\mathbf{P}$ & \\
\hline Right knee & $101.20 \pm 3.30$ & $103.40 \pm 3.49$ & 0.49 & $105.50 \pm 3.40$ & $104.10 \pm 3.55$ & 0.15 & 0.10 \\
\hline Left knee & $100.90 \pm 2.53$ & $104.90 \pm 3.76$ & 0.12 & $102.90 \pm 3.22$ & $105.00 \pm 2.72$ & 0.10 & 0.43 \\
\hline
\end{tabular}

CG: control group; TG: treatment group; SE: standard error.

The cumulative effects of WBVE on the ROM of both knees (i.e., value of ROM before the first session vs. the value before the last session) is reported in Table 4 . Although no significant differences were detected in the TG or CG, an improvement of 7.5 and 13.51 degrees in ROM was observed in the TG on the left and right knee, respectively. Moreover, the \%AROM of the right knee of the participants in the CG decreased slightly (98.53\%), and that of the left knee increased $(105.79 \%)$. The \%AROM of the right and left knees of the participants in the TG increased importantly $(114.29 \%$ and $107.44 \%$, respectively).

Table 4. Cumulative effects on range of the motion of right and left knees before the first session vs. before the last session.

\begin{tabular}{|c|c|c|c|c|c|c|c|}
\hline \multirow{2}{*}{ Knee } & \multicolumn{3}{|c|}{ CG } & \multicolumn{3}{|c|}{ TG } & \multirow{2}{*}{$\begin{array}{c}\mathrm{CG} \times \mathrm{TG} \\
\mathbf{P}\end{array}$} \\
\hline & $\begin{array}{c}\text { Before } \\
\text { Mean } \pm \text { SE } \\
\text { (Degree) }\end{array}$ & $\begin{array}{c}\text { After } \\
\text { Mean } \pm \text { SE } \\
\text { (Degree) }\end{array}$ & $\mathbf{P}$ & $\begin{array}{c}\text { Before } \\
\text { Mean } \pm \text { SE } \\
\text { (Degree) }\end{array}$ & $\begin{array}{c}\text { After } \\
\text { Mean } \pm \text { SE } \\
\text { (Degree) }\end{array}$ & $\mathbf{P}$ & \\
\hline Right knee & $102.70 \pm 3.01$ & $101.20 \pm 3.30$ & 0.62 & $94.49 \pm 4.43$ & $108.00 \pm 3.39$ & 0.09 & 0.07 \\
\hline Left knee & $95.37 \pm 4.28$ & $100.90 \pm 2.53$ & 0.64 & $100.80 \pm 2.64$ & $108.30 \pm 2.59$ & 0.07 & 0.27 \\
\hline
\end{tabular}

CG: control group; TG: treatment group; SE: standard error.

Using sEMG, Table 5 shows the response of the vastus lateralis muscle of both legs to the acute effect of WBVE in the first session, in \%RMS. No significant effects were found (left or right legs) in TG or CG.

Table 5. Acute effects on electromyography (\%RMS) of vastus lateralis muscles (right and left) in the first session.

\begin{tabular}{cccc}
\hline \multirow{2}{*}{ Muscle } & CG & TG & \multirow{2}{*}{ P } \\
\cline { 2 - 3 } & Mean \pm SE \%RMS & Mean \pm SE \%RMS & \\
\hline VL right & $93.59 \pm 5.50$ & $102.10 \pm 3.58$ & 0.28 \\
VL left & $98.65 \pm 3.21$ & $94.91 \pm 3.66$ & 0.99 \\
\hline
\end{tabular}

CG: control group; TG: treatment group; SE: standard error; \%RMS: percentage of the root mean square; VL: vastus lateralis muscle.

The acute effects of WBVE on sEMG of the vastus lateralis muscles in the last session are shown in Table 6. Significant increases $(p<0.05)$ were observed on the \%RMS of vastus lateralis muscles on both legs of the TG relative to the CG. 
Table 6. Acute effects on electromyography (\%RMS) of vastus lateralis muscles (right and left) in the last session.

\begin{tabular}{cccc}
\hline \multirow{2}{*}{ Muscle } & CG & TG & \multirow{2}{*}{ P } \\
\cline { 2 - 3 } & Mean \pm SE \% RMS & Mean \pm SE \% RMS & \\
\hline VL right & $95.22 \pm 3.18$ & $108.00 \pm 5.07$ & $0.008^{*}$ \\
VL left & $96.57 \pm 3.69$ & $106.20 \pm 3.53$ & $0.02 *$ \\
\hline
\end{tabular}

CG: control group; TG: treatment group; SE: standard error; \%RMS: percentage of the root mean square; VL: vastus lateralis muscle; $\mathrm{p} \leq 0.05^{*}$.

The cumulative effects on sEMG (i.e., \%RMS of the vastus lateralis muscle of right and left legs measured before the first session and before the last session) are shown in Table 7. The vastus lateralis muscle activity was not altered in either leg for either of the groups.

Table 7. Cumulative effects on electromyography (\%RMS) of vastus lateralis muscle (right and left).

\begin{tabular}{cccc}
\hline \multirow{2}{*}{ Muscle } & CG & TG & \multirow{2}{*}{ P } \\
\cline { 2 - 3 } & Mean \pm SE \% RMS & Mean \pm SE \% RMS & \\
\hline VL right & $99.38 \pm 5.76$ & $105.70 \pm 5.40$ & 0.63 \\
VL left & $97.10 \pm 4.03$ & $110.60 \pm 7.87$ & 0.26 \\
\hline
\end{tabular}

CG: control group; TG: treatment group; SE: standard error; \%RMS: percentage of the root mean square; VL: vastus lateralis muscle.

\section{Discussion}

All the individuals recruited in the current study presented an increased waist circumference (Table 1); according to the IDF, this is the first criteria followed by a set of two or more metabolic abnormalities to characterize MetS [1].

There is an association between the negative effect of body adiposity and muscle function, with more severe impairment in metabolic disease with IMAT accumulation impacting physical performance [5]. Insulin resistance and type 2 diabetes mellitus are highly prevalent in individuals with MetS [1], and are associated with an infiltration of adipose tissue in skeletal muscles [50]. These features lead to a reduction in the power output and strength per unit of muscle mass. Hilton et al. [51] showed that marked IMAT was inversely correlated with muscle power, strength, and physical performance scores. Lafortuna et al. also reported a negative effect of metabolic abnormalities related to impaired glucose homeostasis on motor performance [52]. IMAT is now recognized as an important predictor of muscle metabolism and function, and also appears to be a modifiable muscle risk factor. Exercise and physical activity appear to be effective countermeasures against increases in IMAT [4]. In addition, exercise is also reported to be an important intervention to improve the physical condition of MetS individuals [26]. Moreover, a simple and useful kind of exercise generated in individuals exposed to mechanical vibration, WBVE, could prove useful for these individuals.

\subsection{Effect of Whole Body Vibration Exercise (WBVE) on Range of Motion (ROM)}

In our study, there was no improvement in knee ROM in individuals with MetS exposed to WBVE. No increase in ROM was observed in a single session or even in a 5-weeks treatment. Our results are in agreement with the findings of Neto et al. (2017), who did not find an increase in ROM in knee flexion in individuals with knee osteoarthritis (KOA) [47]. Wang et al., comparing quadriceps resistance exercise alone and associated with WBVE, observed a significantly greater improvement in active knee flexion and extension at 2 and 4 weeks after quadriceps resistance exercise combined with WBVE in individuals with KOA [53]. Authors have reported that higher body fat is also associated with poor physical performance and subsequent disability than is muscle mass reduction [4,54]. This could justify the results of the current study. In addition, obesity can modify the movements and force response of 
these individuals. Del Porto et al. reported that some adaptations of shifts in the body's total ROM are difficult to adjust without compromising normal patterns of movement in obese individuals [55]. Putting together these considerations, it is possible to justify no improvements in the ROM of the knees in the population evaluated in our work. By contrast, Yang et al., in a longitudinal study of 8 weeks with WBVE in individuals with multiple sclerosis, observed a significant increase in the active ROM assessed at the ankle joint bilaterally, in plantar flexion $(p=0.002)$ and dorsiflexion $(p=0.003)$. Yang et al. concluded that WBVE increased the flexibility of the ankle joint, reduced the fear of falling, and strengthened the bones [38]. Although Krause et al. observed no changes in the ankle joint excursion immediately after a 1-min bout of WBVE, they found an increase in the knee joint active angular excursion during flexion and extension $(\mathrm{p}<0.01)$ in individuals with cerebral palsy [29]. In another study performed in children with cerebral palsy, a significant increase in ROM was detected immediately after treatment with WBVE [44]. These conflicting results about the effect of WBVE on the ROM of joints could be associated with the variability of the protocols and the populations evaluated.

\subsection{Effect of WBVE on $S E M G$}

In the present study, significant changes in the electromyographic signal of the VL muscle on both legs were observed in the acute effect of the last session of the 5-week WBVE intervention (Table 6). This is in agreement with other authors that have shown improvement in muscle activity due to WBVE intervention in different muscles in individuals with various diseases [27], such as acute and chronic stroke [30,56], spinal cord injury [24], Friedreich's ataxia [57], and cerebral palsy [29]. Liao et al. detected changes in muscle activity even in individuals with paresis [30]. Furthermore, increased muscular activity was also observed in healthy individuals [34,58]. Borges et al. found that WBVE increased the sEMG amplitude of the VL muscle during an isometric semi-squat exercise in active woman [34]. A systematic review has analyzed the effects of WBVE in lower limbs' neuromuscular activity, suggesting that there was a greater recruitment of motor units after WBVE [27].

In the current study, no effects were observed in \%RMS in the acute effect of the first session or in the cumulative effect (Tables 5 and 7). Considering the acute effect, Annino et al. (2017) also reported no alteration in the sEMG of the VL muscle when healthy individuals were exposed to 10 minutes of WBV at $35 \mathrm{~Hz}$ [59]. Borges et al. (2016) evaluated the immediate effects of WBV in healthy individuals with frequencies of 30 and $50 \mathrm{~Hz}$, and no significant differences in the value of RMS were found [60]. Considering the cumulative effect (Table 7), the present study found no significant changes in the electromyographic signal of the VL muscle in either leg. Rubio-Arias et al. (2018) also observed no statistically significant differences in body composition or muscle architecture variables, nor changes in muscle activity during the take-off phase of the vastus lateralis pre- versus post-training in a 6-week WBVE treatment with a frequency between 30 and $45 \mathrm{~Hz}$ in healthy individuals [61].

Some limitations of this study should be pointed out, such as the relatively small number of participants; however, the statistical power was $95 \%$. Moreover, although we evaluated both lower limbs, we did not register which lower limb was the dominant one. Nevertheless, a strength of this work is the improvement in neuromuscular activity; this finding may have positive clinical implications by improving daily activities in individuals with MetS.

In conclusion, WBVE can be a modality of exercise to increase the neuromuscular activity of the VL muscle using a 5-week protocol. An increase in ROM of the knees in individuals with MetS was not observed with the same protocol. WBVE appears to be an adequate strategy to improve neuromuscular activity in individuals with MetS, overweight, and obesity, being a potential opportunity for the management of physical impairment in these individuals. Nevertheless, further additional studies with larger samples and more prolonged periods of WBVE exposure are needed to confirm our preliminary findings.

Author Contributions: Conceptualization, M.B.-F.; Data curation, C.R.d.S.-G., D.d.C.d.S.-C., L.L.P.-D., E.M.-M., M.E.S.M.-O., Y.T.-S., A.P.d.S.L., J.A.B., M.J.d.S.P., V.L.X., A.G.d.M., L.F.F.D.S., A.R.-S., A.F.-S., G.M.G.-L., M.C.M.-F., A.d.R.P.M., T.A., A.C.R.L., V.A.M., A.S. and M.B.-F.; Formal analysis, M.J.d.S.P., V.L.X., and R.T.; Funding 
acquisition, M.B.-F.; Investigation, C.R.d.S.-G., D.d.C.d.S.-C., L.L.P.-D., E.M.-M., M.E.S.M.-O., Y.T.-S., A.P.d.S.L., A.G.d.M., L.F.F.D.S., A.R.-S., A.F.-S., G.M.G.-L., M.C.M.-F. and A.d.R.P.M.; Methodology, C.R.d.S.-G., D.d.C.d.S.-C., L.L.P.-D., E.M.-M., M.E.S.M.-O., Y.T.-S., A.P.d.S.L., A.G.d.M., L.F.F.D.S., A.R.-S., A.F.-S., G.M.G.-L., M.C.M.-F. and A.d.R.P.M.; Supervision, D.d.C.d.S.-C.; Writing—original draft, C.R.d.S.-G. and Y.T.-S.; Writing—review \& editing, D.d.C.d.S.-C., J.A.B., R.T., T.A., A.C.R.L., V.A.M., A.S. and M.B.-F.

Funding: This research was funded by Coordenação de Aperfeiçoamento de Pessoal de Nível Superior (CAPES) - Finance Code 001, and the Conselho Nacional de Desenvolvimento Científico e Tecnológico (CNPq).

Acknowledgments: The authors are grateful for the support of the Fundação Carlos Chagas Filho de Amparo à Pesquisa do Estado do Rio de Janeiro (FAPERJ), the Coordenação de Aperfeiçoamento de Pessoal de Nível Superior (CAPES)-Finance Code 001, and the Conselho Nacional de Desenvolvimento Científico e Tecnológico (CNPq).

Conflicts of Interest: The authors declare that there is no conflict of interests regarding the publication of this paper.

\begin{tabular}{|c|c|}
\hline \multicolumn{2}{|c|}{ Abbreviations } \\
\hline BMI & body mass index \\
\hline CG & control group \\
\hline HUPE & Hospital Universitário Pedro Ernesto \\
\hline IDF & International Diabetes Federation \\
\hline IMAT & intramuscular adipose tissue \\
\hline KOA & knee osteoarthritis \\
\hline LAVIMPI & $\begin{array}{l}\text { Laboratório de Vibrações Mecânicas e Práticas } \\
\text { Integrativas }\end{array}$ \\
\hline LEE & Laboratório de Epidemiologia e Estatística \\
\hline MetS & Metabolic syndrome \\
\hline ReBEC & Registro Brasileiro de Ensaios clínicos \\
\hline RMS & root mean square \\
\hline $\mathrm{ROM}$ & range of motion \\
\hline sEMG & surface electromyography \\
\hline SENIAM & $\begin{array}{l}\text { Surface ElectroMyoGraphy for the } \\
\text { Non-Invasive Assessment of Muscles }\end{array}$ \\
\hline TG & treatment group \\
\hline UERJ & Universidade do Estado do Rio de Janeiro \\
\hline VL & vastus lateralis \\
\hline VP & vibrating platform \\
\hline WBVE & Whole body vibration exercise \\
\hline WC & waist circumference \\
\hline$\mu \mathrm{V}$ & microvolts \\
\hline
\end{tabular}

\section{References}

1. Alberti, K.G.M.M.; Eckel, R.H.; Grundy, S.M.; Zimmet, P.Z.; Cleeman, J.I.; Donato, K.A.; Fruchart, J.C.; James, W.P.T.; Loria, C.M.; Smith, S.C. Harmonizing the metabolic syndrome: A joint interim statement of the international diabetes federation task force on epidemiology and prevention; National heart, lung, and blood institute; American heart association; World heart federation; International Atherosclerosis Society; and International Association for the Study of Obesity. Circulation 2009, 120, 1640-1645. [PubMed]

2. Worachartcheewan, A.; Schaduangrat, N.; Prachayasittikul, V.; Nantasenamat, C. Data mining for the identification of metabolic syndrome status. EXCLI J. 2018, 17, 72-88. [PubMed]

3. Yang, C.S.; Wang, H.; Sheridan, Z.P. Studies on prevention of obesity, metabolic syndrome, diabetes, cardiovascular diseases and cancer by tea. J. Food Drug Anal. 2018, 26, 1-13. [CrossRef] [PubMed]

4. Addison, O.; Marcus, R.L.; Lastayo, P.C.; Ryan, A.S. Intermuscular fat: A review of the consequences and causes. Int. J. Endocrinol. 2014, 2014, 309570. [CrossRef]

5. Tuttle, L.J.; Sinacore, D.R.; Mueller, M.J. Intermuscular adipose tissue is muscle specific and associated with poor functional performance. J. Aging Res. 2012, 2012, 172957. [CrossRef]

6. Bollinger, L.M. Potential contributions of skeletal muscle contractile dysfunction to altered biomechanics in obesity. Gait Posture 2017, 56, 100-107. [CrossRef] 
7. Capodaglio, P.; Castelnuovo, G.; Brunani, A.; Vismara, L.; Villa, V.; Maria Capodaglio, E. Functional limitations and occupational issues in obesity: A review. Int. J. Occup. Saf. Ergon. 2010, 16, 507-523. [CrossRef]

8. Ghroubi, S.; Kossemtini, W.; Mahersi, S.; Elleuch, W.; Chaabene, M.; Elleuch, M.H. Contribution of isokinetic muscle strengthening in the rehabilitation of obese subjects. Ann. Phys. Rehabil. Med. 2016, 59, 87-93. [CrossRef]

9. Fabris, S.M.; Faintuch, J.; Brienze, S.L.A.; Brito, G.B.; Sitta, I.S.; Mendes, E.L.P.; Fonseca, I.C.B.; Cecconello, I. Are knee and foot orthopedic problems more disabling in the superobese? Obes. Surg. 2013, 23, 201-204. [CrossRef]

10. Gadducci, A.; de Cleva, R.; Santarém, G.; Silva, P.; Greve, J.; Santo, M. Muscle strength and body composition in severe obesity. Clinics 2017, 72, 272-275. [CrossRef]

11. Abella, V.; Scotece, M.; Conde, J.; López, V.; Lazzaro, V.; Pino, J.; Gómez-Reino, J.J.; Gualillo, O. Adipokines, metabolic syndrome and rheumatic diseases. J. Immunol. Res. 2014, 25, 343746. [CrossRef] [PubMed]

12. Nye, N.S.; Kafer, D.S.; Olsen, C.; Carnahan, D.H.; Crawford, P.F. Abdominal Circumference Versus Body Mass Index as Predictors of Lower Extremity Overuse Injury Risk. J. Phys. Act. Health 2018, 15, 127-134. [CrossRef] [PubMed]

13. Wearing, S.C.; Hennig, E.M.; Byrne, N.M.; Steele, J.R.; Hills, A.P. Musculoskeletal disorders associated with obesity: A biomechanical perspective. Obes. Rev. 2006, 7, 239-250. [CrossRef] [PubMed]

14. Sowers, M.R.; Karvonen-Gutierrez, C.A. The evolving role of obesity in knee osteoarthritis. Curr. Opin. Rheumatol. 2010, 22, 533-537. [CrossRef]

15. Holla, J.F.M.; Steultjens, M.P.M.; van der Leeden, M.; Roorda, L.D.; Bierma-Zeinstra, S.M.A.; den Broeder, A.A.; Dekker, J. Determinants of range of joint motion in patients with early symptomatic osteoarthritis of the hip and/or knee: An exploratory study in the CHECK cohort. Osteoarthr. Cart. 2011, 19, 411-419. [CrossRef]

16. Rowe, P.J.; Myles, C.M.; Walker, C.; Nutton, R. Knee joint kinematics in gait and other functional activities measured using flexible electrogoniometry: How much knee motion is sufficient for normal daily life? Gait Posture 2000, 12, 143-155. [CrossRef]

17. Clarkson, H. Musculoskeletal Assessment: Joint Range of Motion and Manual Muscle Strength, 2th ed.; Lippincott Wiliams and Wilkin: Philadelphia, PA, USA, 2002.

18. Pajoutan, M.; Ghesmaty Sangachin, M.; Cavuoto, L.A. Central and peripheral fatigue development in the shoulder muscle with obesity during an isometric endurance task. BMC Musculoskelet Disord 2017, 18, 314. [CrossRef]

19. Zdziarski, L.A.; Wasser, J.G.; Vincent, H.K. Chronic pain management in the obese patient: A focused review of key challenges and potential exercise solutions. J. Pain Res. 2015, 8, 63-77.

20. Alvarez-Alvarado, S.; Jaime, S.J.; Ormsbee, M.J.; Campbell, J.C.; Post, J.; Pacilio, J.; Figueroa, A. Benefits of whole-body vibration training on arterial function and muscle strength in young overweight/obese women. Hypertens. Res. 2017, 40, 487-492. [CrossRef]

21. Patel, V.S.; Ete Chan, M.; Rubin, J.; Rubin, C.T. Marrow Adiposity and Hematopoiesis in Aging and Obesity: Exercise as an Intervention. Curr. Osteoporos. Rep. 2018, 16, 105-115. [CrossRef]

22. Rauch, F.; Sievanen, H.; Boonen, S.; Cardinale, M.; Degens, H.; Felsenberg, D.; Roth, J.; Schoenau, E.; Verschueren, S.; Rittweger, J. Reporting whole-body vibration intervention studies: Recommendations of the International Society of Musculoskeletal and Neuronal Interactions. J. Musculoskelet. Neuronal Interact. 2010, 10, 193-198. [PubMed]

23. Pinto, N.S.; Monteiro, M.B.; Arthur, A.P.; Paiva, D.N.; Meyer, P.F.; Santos-Filho, S.D.; Marín, P.J.; Bernardo-Filho, M. Effectiveness of a protocol involving acute whole-body vibration exercises in an adult and health individual with delayed-onset muscle soreness observed after running: A case repor. J. Med. Med. Sci. 2011, 2, 612-617.

24. Menéndez, H.; Ferrero, C.; Martín-Hernández, J.; Figueroa, A.; Marín, P.J.; Herrero, A.J. Acute effects of simultaneous electromyostimulation and vibration on leg blood flow in spinal cord injury. Spinal Cord 2016, 54, 383-389. [CrossRef] [PubMed]

25. Carvalho-Lima, R.P.; Sá-Caputo, D.C.; Moreira-Marconi, E.; Dionello, C.; Paineiras-Domingos, L.L.; Sousa-Gonçalves, C.R.; Morel, D.S.; Frederico, E.H.; Neves, M.F.; Oliveira, R.; et al. Quality of life of patients with metabolic syndrome is improved after Whole Body Vibration Exercises. Afr. J. Tradit. Complement. Altern. Med. 2017, 14, 59-65. [CrossRef] 
26. Sá-Caputo, D.d.C.; Ronikeili-Costa, P.; Carvalho-Lima, R.P.; Bernardo, L.C.; Bravo-Monteiro, M.O.; Costa, R.; Moraes-Silva, J.d.; Paiva, D.N.; Machado, C.B.; Mantilla-Giehl, P.; et al. Whole Body Vibration Exercises and the Improvement of the Flexibility in Patient with Metabolic Syndrome. Rehabil. Res. Prac. 2014, 2014, 1-10. [CrossRef]

27. Dionello, C.F.; De Souza, P.L.; Sá-Caputo, D.; Morel, D.S.; Moreira-Marconi, E.; Paineiras-Domingos, L.L.; Frederico, E.H.F.F.; Guedes-Aguiar, E.; Paiva, P.D.C.; Taiar, R.; et al. Do whole body vibration exercises affect lower limbs neuromuscular activity in populations with a medical condition? Restor. Neurol. Neurosc. 2017, 35, 667-681. [CrossRef]

28. Herrero, A.J.; Martín, J.; Martín, T.; García-López, D.; Garatachea, N.; Jiménez, B.; Marín, P.J. Whole-body vibration alters blood flow velocity and neuromuscular activity in Friedreich's ataxia. Clin. Physiol. Funct. Imaging 2011, 31, 139-144. [CrossRef]

29. Krause, A.; Schoenau, E.; Gollhofer, A.; Duran, I.; Ferrari-Malik, A.; Freyler, K.; Ritzmann, R. Alleviation of Motor Impairments in Patients with Cerebral Palsy: Acute Effects of Whole-body Vibration on Stretch Reflex Response, Voluntary Muscle Activation and Mobility. Front. Neurol. 2017, 8, 1-11. [CrossRef]

30. Liao, L.-R.; Ng, G.Y.F.; Jones, A.Y.M.; Huang, M.-Z.; Pang, M.Y.C. Whole-Body Vibration Intensities in Chronic Stroke: A Randomized Controlled Trial. Med. Sci. Sports Exerc. 2016, 48, 1227-1238. [CrossRef]

31. Van Ruymbeke, B.; Boone, J.; Coorevits, P.; Vanderstraeten, G.; Bourgois, J. Whole-body vibration in breast cancer survivors: A pilot study exploring its effects on muscle activity and subjectively perceived exertion. Int. J. Rehabil. Res. 2014, 37, 371-374. [CrossRef]

32. Perchthaler, D.; Horstmann, T.; Grau, S. Variations in neuromuscular activity of thigh muscles during whole-body vibration in consideration of different biomechanical variables. J. Sci. Med. Sport 2013, 12, 439-446.

33. Fattorini, L.; Tirabasso, A.; Lunghi, A.; Di Giovanni, R.; Sacco, F.; Marchetti, E. Muscular forearm activation in hand-grip tasks with superimposition of mechanical vibrations. J. Electromyogr. Kinesiol. 2016, 26, 143-148. [CrossRef] [PubMed]

34. Borges, D.T.; Macedo, L.B.; Lins, C.A.A.; Sousa, C.O.; Brasileiro, J.S. Effects of Whole Body Vibration on the Neuromuscular Amplitude of Vastus Lateralis Muscle. J. Sci. Med. Sport 2017, 16, 414-420.

35. Mosier, E.M.; Herda, T.J.; Trevino, M.A.; Miller, J.D. The influence of prolonged vibration on motor unit behavior. Muscle Nerve 2017, 55, 500-507. [CrossRef]

36. Simsek, D. Different fatigue-resistant leg muscles and EMG response during whole-body vibration. J. Electromyogr. Kinesiol. 2017, 37, 147-154. [CrossRef]

37. Cheng, H.-Y.K.; Ju, Y.-Y.; Chen, C.-L.; Chuang, L.-L.; Cheng, C.-H. Effects of whole body vibration on spasticity and lower extremity function in children with cerebral palsy. Hum. Mov. Sci. 2015, 39, 65-72. [CrossRef]

38. Yang, F.; Finlayson, M.; Bethoux, F.; Su, X.; Dillon, L.; Maldonado, H.M. Effects of controlled whole-body vibration training in improving fall risk factors among individuals with multiple sclerosis: A pilot study. Disabil. Rehabil. 2018, 40, 553-560. [CrossRef]

39. Wang, P.; Yang, L.; Li, H.; Lei, Z.; Yang, X.; Liu, C.; Jiang, H.; Zhang, L.; Zhou, Z.; Reinhardt, J.D.; et al. Effects of whole-body vibration training with quadriceps strengthening exercise on functioning and gait parameters in patients with medial compartment knee osteoarthritis: A randomised controlled preliminary study. Physiotherapy (UK) 2016, 102, 86-92. [CrossRef]

40. LEE-Laboratório de Epidemiologia e Estatística. Available online: http://www.lee.dante.br/pesquisa.html (accessed on 10 October 2018).

41. O'Keefe, K.; Orr, R.; Huang, P.; Selvadurai, H.; Cooper, P.; Munns, C.F.; Singh, M.A.F. The effect of whole body vibration exposure on muscle function in children with cystic fibrosis: A pilot efficacy trial. J. Clin. Med. Res. 2013, 5, 205-216. [CrossRef]

42. Cardinale, M.; Wakeling, J. Whole body vibration exercise: Are vibrations good for you? J. Sports Med. 2005, 39, 585-589. [CrossRef]

43. WHO. Physical status: The use and interpretation of anthropometry. Report of a WHO Expert Committee. WHO Tech. Rep. Ser. 1995, 854, 1-452.

44. Dos Santos, R.A.; Derhon, V.; Brandalize, M.; Brandalize, D.; Rossi, L.P. Evaluation of knee range of motion: Correlation between measurements using a universal goniometer and a smartphone goniometric application. J. Bodyw. Mov. Ther. 2017, 21, 699-703. [CrossRef] [PubMed] 
45. Milanese, S.; Gordon, S.; Buettner, P.; Flavell, C.; Ruston, S.; Coe, D.; O'Sullivan, W.; McCormack, S. Reliability and concurrent validity of knee angle measurement: Smart phone app versus universal goniometer used by experienced and novice clinicians. Man. Ther. 2014, 19, 569-574. [CrossRef] [PubMed]

46. Marks, R. Knee Osteoarthritis and Exercise Adherence: A Review. Curr. Aging Sci. 2012, 5, 72-83. [CrossRef] [PubMed]

47. Neto, S.B.S.; Marconi, E.M.; Kutter, C.R.; Frederico, E.H.F.F.F.; De Paiva, P.d.C.; Meyer, P.F.; Chang, S.; Sá-Caputo, D.; Bernardo-Filho, M. Beneficial effects of whole body mechanical vibration alone or combined with auriculotherapy in the pain and in flexion of knee of individuals with knee osteoarthritis. Acupunct. Electro Ther. Res. 2017, 42, 185-201. [CrossRef]

48. Hermens, H.J.; Freriks, B.; Disselhorst-Klug, C.; Rau, G. Development of recommendations for SEMG sensors and sensor placement procedures. J. Electromyogr. Kinesiol. 2000, 10, 361-374. [CrossRef]

49. Lee, T.-H.; Choi, J.-D.; Lee, N.-G. Activation timing patterns of the abdominal and leg muscles during the sit-to-stand movement in individuals with chronic hemiparetic stroke. J. Phys. Ther. Sci. 2015, 27, 3593-3595. [CrossRef]

50. Tomlinson, D.J.; Erskine, R.M.; Winwood, K.; Morse, C.I.; Onambélé, G.L. The impact of obesity on skeletal muscle architecture in untrained young vs. old women. J. Anat. 2014, 225, 675-684. [CrossRef]

51. Hilton, T.N.; Tuttle, L.J.; Bohnert, K.L.; Mueller, M.J.; Sinacore, D.R. Excessive Adipose Tissue Infiltration in Skeletal Muscle in Individuals With Obesity, Diabetes Mellitus, and Peripheral Neuropathy: Association With Performance and Function. Phys. Ther. 2008, 88, 1336-1344. [CrossRef]

52. Lafortuna, C.L.; Prinelli, F.; Adorni, F.; Agosti, F.; De Col, A.; Sartorio, A. Effect of mechanical and metabolic factors on motor function and fatigue in obese men and women: A cross-sectional study. J. Endocrinol. Investig. 2013, 36, 1062-1068.

53. Wang, P.; Yang, L.; Liu, C.; Wei, X.; Yang, X.; Zhou, Y.; Jiang, H.; Lei, Z.; Reinhardt, J.D.; He, C. Effects of Whole Body Vibration Exercise associated with Quadriceps Resistance Exercise on functioning and quality of life in patients with knee osteoarthritis: A randomized controlled trial. Clin. Rehabil. 2016, 30, 1074-1087. [CrossRef] [PubMed]

54. Rolland, Y.; Lauwers-Cances, V.; Cristini, C.; van Kan, G.A.; Janssen, I.; Morley, J.E.; Vellas, B. Difficulties with physical function associated with obesity, sarcopenia, and sarcopenic-obesity in community-dwelling elderly women: The EPIDOS ( EPIDemiologie de l'OSteoporose ) Study 1-3. Am. J. Clin. Nutr. 2009, 89, 1895-1900. [CrossRef] [PubMed]

55. Porto, H.C.D.; Pechak, C.M.; Smith, D.R.; Reed-Jones, R.J. Biomechanical Effects of Obesity on Balance. Int. J. Exerc. Sci. 2012, 5, 301-320.

56. Tihanyi, T.K.; Horváth, M.; Fazekas, G.; Hortobágyi, T.; Tihanyi, J. One session of whole body vibration increases voluntary muscle strength transiently in patients with stroke. Clin. Rehabil. 2007, 21, 782-793. [CrossRef]

57. Herrero, A.J.; Menéndez, H.; Gil, L.; Martín, J.; Martín, T.; García-López, D.; Gil-Agudo, Á.; Marín, P.J. Effects of whole-body vibration on blood flow and neuromuscular activity in spinal cord injury. Spinal Cord 2011, 49, 554-559. [CrossRef]

58. Avelar, N.C.P.; Ribeiro, V.G.C.; Mezêncio, B.; Fonseca, S.F.; Tossige-Gomes, R.; da Costa, S.J.; Szmuchrowski, L.; Gripp, F.; Coimbra, C.C.; Lacerda, A.C.R. Influence of the knee flexion on muscle activation and transmissibility during whole body vibration. J. Electromyogr. Kinesiol. 2013, 23, 844-850. [CrossRef]

59. Annino, G.; Iellamo, F.; Palazzo, F.; Fusco, A.; Lombardo, M.; Campoli, F.; Padua, E. Acute changes in neuromuscular activity in vertical jump and flexibility after exposure to whole body vibration. Medicine (US) 2017, 96, e7629. [CrossRef]

60. Borges, D.T.; Macedo, L.B.; Lins, C.A.A.; Brasileiro, J.S. Immediate effects of whole-body vibration on neuromuscular performance of quadriceps and oscillation of the center of pressure: A randomized controlled trial. Man. Ther. 2016, 25, 62-68. [CrossRef]

61. Rubio-Arias, J.Á.; Ramos-Campo, D.J.; Esteban, P.; Martínez, F.; Jiménez, J.F. Effect of 6-weeks WBVT on the behaviour of the lower limb muscle fibres during vertical jumping. J. Sports Sci. 2018, 36, 398-406. [CrossRef]

(C) 2019 by the authors. Licensee MDPI, Basel, Switzerland. This article is an open access article distributed under the terms and conditions of the Creative Commons Attribution (CC BY) license (http://creativecommons.org/licenses/by/4.0/). 